Article

\title{
Associations between Socio-Demographic Factors and Hypertension Management during the COVID-19 Pandemic: Preliminary Findings from Malaysia
}

\author{
Mohamed Hassan Elnaem ${ }^{1,2, *}{ }^{\oplus}$, Nur Hasyimah Kamarudin ${ }^{1}\left(\mathbb{D}\right.$, Nabeel Kashan Syed ${ }^{3}{ }^{(0}$, Hasniza Zaman Huri ${ }^{4}(\mathbb{0}$, \\ Inderpal Singh Dehele ${ }^{5}$ and Ejaz Cheema ${ }^{6}$ \\ 1 Department of Pharmacy Practice, Faculty of Pharmacy, International Islamic University Malaysia, \\ Kuantan 25710, Malaysia; shima.shi98@gmail.com \\ 2 Quality Use of Medicines Research Group, Faculty of Pharmacy, International Islamic University Malaysia, \\ Kuantan 25710, Malaysia \\ 3 Pharmacy Practice Research Unit, Department of Clinical Pharmacy, Faculty of Pharmacy, Jazan University, \\ Jizan 45142, Saudi Arabia; nabeelsyed2020@outlook.com \\ 4 Department of Clinical Pharmacy and Pharmacy Practice, Faculty of Pharmacy, Universiti Malaya, \\ Kuala Lumpur 50603, Malaysia; hasnizazh@um.edu.my \\ updates \\ Citation: Elnaem, M.H.; Kamarudin, \\ N.H.; Syed, N.K.; Huri, H.Z.; Dehele, \\ I.S.; Cheema, E. Associations between \\ 5 School of Pharmacy, University of Birmingham, Birmingham B15 2TT, UK; I.S.Dehele@bham.ac.uk \\ 6 School of Pharmacy, University of Management and Technology, Lahore 54770, Pakistan; \\ cheemaejaz@hotmail.com \\ * Correspondence: drmelnaem@iium.edu.my or drmelnaem@gmail.com
} Socio-Demographic Factors and Hypertension Management during the COVID-19 Pandemic: Preliminary Findings from Malaysia. Int. J. Environ. Res. Public Health 2021, 18, 9306. https://doi.org/10.3390/ ijerph18179306

Academic Editors: Ana Isabel Cobo-Cuenca, Juan Manuel Carmona-Torres, Diana Patricia Pozuelo-Carrascosa, José Alberto Laredo-Aguilera and Pedro Ángel Latorre Román

Received: 4 July 2021

Accepted: 29 August 2021

Published: 3 September 2021

Publisher's Note: MDPI stays neutral with regard to jurisdictional claims in published maps and institutional affiliations.

Copyright: (c) 2021 by the authors. Licensee MDPI, Basel, Switzerland. This article is an open access article distributed under the terms and conditions of the Creative Commons Attribution (CC BY) license (https:// creativecommons.org/licenses/by/ $4.0 /)$.
Abstract: The perspectives of hypertensive patients on the state of hypertension control during the ongoing pandemic restrictions have not been extensively studied in Malaysia. Therefore, this study aimed to assess the impact of socio-demographic factors, health literacy, and adherence on the overall hypertension management in a group of Malaysian hypertensive patients during the COVID-19 pandemic. An anonymous, online cross-sectional study was conducted over three months that involved a group of Malaysian adults with hypertension. A validated, self-administered 30-item questionnaire was prepared in Malay and English languages on Google Forms. The link was then distributed to participants on social media (Facebook and WhatsApp). Following survey validation, a pilot study with 30 participants who met the inclusion criteria was carried out. The total scores for health literacy, adherence, and pandemic impact on hypertension control were calculated and compared across all independent variables. In a total of 144 study participants, controlled blood pressure was reported in $77 \%(\mathrm{~N}=111)$. There were good levels of adherence and health literacy scores but moderate levels of pandemic impact scores. The total adherence scores showed a statistically significant difference between age groups $\left(\chi^{2}=6.48, p=0.039\right)$ and those who reported having controlled and uncontrolled blood pressure $(U=1116, p=0.001)$. Moreover, the analysis revealed statistically significant differences in total pandemic impact scores based on the age group $\left(\chi^{2}=15.008, p=0.001\right)$, household income $\left(\chi^{2}=6.887, p=0.032\right)$, employment $(\mathrm{U}=1712, p=0.006)$, and marital status $(\mathrm{U}=520.5, p<0.001)$. The youngest age group (18-39) years, the lowest income group, unemployed and unmarried individuals, had significantly higher pandemic impact scores. This denotes that those individuals were more prone to be negatively affected by the pandemic regarding their hypertension management. Most participants reported relatively controlled blood pressure and good levels of health literacy as well as adherence amidst the pandemic. To a moderate extent, study participants perceived that the pandemic had a negative effect on hypertension management. The perceived negative impact of the pandemic was attributed to several socio-demographic factors, such as age, household income, employment, and marital status.

Keywords: hypertension; pandemic; perspectives; blood pressure control; health literacy; adherence; COVID-19 pandemic; Malaysia 


\section{Introduction}

Hypertension is one of the most prevalent non-communicable diseases (NCDs), with a global prevalence of $20 \%$ to $25 \%$, according to WHO 2015 key facts sheets [1]. Due to its asymptomatic nature, hypertension or high blood pressure is often referred to as a silent killer disease [2]. Maintaining proper blood pressure (BP) control is challenging, with a reported success rate of only $40 \%$, although a high proportion of patients receive treatment [3]. Global data shows that less than one in five patients manage to maintain proper BP control [1]. In Malaysia, hypertension is a prevalent healthcare issue where three among every ten individuals have hypertension [4]. Moreover, the analysis of the COVID19 pandemic data showed that a large proportion of hospitalised COVID-19 patients also had hypertension [5]. Those hypertensive patients had poor prognosis with significant need for mechanical ventilation and higher mortality risk [6].

Health literacy and medication adherence are two main challenges for controlling hypertension in clinical settings [7-9]. Health literacy affects a patient's level of self-care, medication knowledge, and adherence [9]. According to the American Heart Association, health literacy can help patients improve their health status, better understand disease processes, and lower their risk of hospitalisation [10]. Additionally, the silent nature of the disease complicates medication adherence, as non-adherence may not immediately manifest as unpleasant symptoms [11]. Thus, adherence has been highlighted as a critical issue in hypertension management, with poor adherence identified as a key contributor to uncontrolled hypertension [12]. This should be a major concern for the healthcare systems, as hypertensive patients with poorly controlled blood pressure are at an increased risk of developing or worsening pre-existing cardiovascular disease (CVD), cerebrovascular, and renal diseases [3].

Globally, most sectors, including healthcare, have been negatively impacted by the COVID-19 pandemic [13]. According to the World Health Organization (WHO) rapid assessment of the impact of COVID-19 pandemic on NCD resources, approximately $75 \%$ of participating countries reported disruptions to NCD services, including hypertension management [14]. Healthcare services for chronic disease patients were at risk of disruptions during the ongoing pandemic. Hypertension, as is the case with other NCDs, requires regular and long-term care [14]. These disruptions must be acknowledged and addressed by the health care providers to help patients with NCD maintain proper control of their conditions [15]. The Hypertension Cardiovascular Outcomes Prevention Evidence in Asia (HOPE Asia) acknowledged that management of hypertension might be affected by the pandemic-related restrictions and thus recommended telemedicine strategies to be implemented [16].

However, the perspectives of hypertensive patients on the state of blood pressure control during the current pandemic restrictions need further investigations. In addition, further information on the important demographic data to be considered in the context of pandemic impact on disease management is still required. Therefore, this study aimed to assess the impact of socio-demographic factors, health literacy, and adherence on the overall hypertension management in a group of Malaysian hypertensive patients during the COVID-19 pandemic.

\section{Materials and Methods}

\subsection{Study Design}

This descriptive anonymous, online, cross-sectional study involving a sample of adults with hypertension in Malaysia was conducted for a period of three months between January and April 2021. The study used a validated, self-administered survey prepared in Malay and English languages on Google Forms and was disseminated on social media. Participants were asked to answer only one of the versions to avoid duplicate responses. 


\subsection{Ethical Approval}

Ethical approval for this study was provided by IIUM Research Ethics Committee (IREC 2020-176). The participation information sheet and informed consent were included in the online survey form. Participants were briefed on the strict confidentiality of their information and the anonymous use of their data for scientific research purposes only. By approving the consent form, participants were deemed to have consented to participate in this research. They were also given the freedom to withdraw their consent at any time during the study.

\subsection{Inclusion and Exclusion Criteria}

Adults aged 18 years old and above with hypertension were eligible to be included in this study. The participants were eligible for inclusion if they had received a diagnosis of hypertension with or without comorbidity before the declaration of the COVID-19 outbreak as a pandemic by the WHO on 11 March 2020 [17]. Pregnant patients were excluded from the study.

\subsection{Sample Size}

Using the Raosoft sample size calculator, assuming an estimated proportion of $72 \%$ based on the most recent estimate from a similar setting [14] and a 95\% confidence interval, and upon confirmation that at least 260 potential respondents had received the survey form, the minimum required sample size was estimated to be 142 .

\subsection{Instrument Structure and Translation}

A self-developed, pre-validated 30-item questionnaire was prepared in Malay and English languages on Google Forms, and the link was then distributed to participants on social media (Facebook and WhatsApp).

The questionnaire comprised of four parts:

- Part 1 (nine items to cover the general socio-demographic details and the average BP reading).

- $\quad$ Part 2 (five statements to assess their health literacy level).

- Part 3 (eight statements to assess their adherence level). This part was developed with permission from the original developer by adopting and adapting Hill-Bone HBP compliance to the high blood pressure therapy scale (HB-HBP) [18].

- Part 4 (eight statements to assess the impact of the pandemic on hypertension control).

The translation from English to Malay was carried out following the forward-backward translation method. These three versions, including the original version, were then compared to ensure consistency before proceeding to the pilot study.

\subsection{Validity Testing}

Five experts in pharmacy practice evaluated the questionnaire's content validity by estimating the content validity index for each item (I-CVI) to ascertain its relevance and clarity. The I-CVI should be at least 0.78 with a minimum of three experts [19]. Any item with I-CVI $<0.78$ for relevance was discarded from the questionnaire, while any item with I-CVI $<0.78$ was improved for better clarity based on the experts' suggestions. For example, an item asked about all the diet recommendations in one statement in the health literacy section. Based on the expert's suggestion, the item was revised to be more concise and focused only on salt restriction. Item 5 in the health literacy section was also rephrased accordingly as per the expert's recommendation. In the first draft, this item did not precisely refer to the duration of the disease or its treatment.

\subsection{Pilot Study and Reliability Testing}

Upon validation, a pilot study was conducted on 30 participants who fulfilled the inclusion criteria. The data obtained from the participants in the pilot study were excluded from the main data analysis. The questionnaire was then tested for its reliability and 
internal consistency. The values of Cronbach's alpha for each part, excluding the first part (Part 1: Socio-demographic details), were calculated to determine the internal consistency. Some items were omitted to obtain Cronbach's alpha values within an acceptable range. The final values of Cronbach's alpha for Part 2 (health literacy level assessment), Part 3 (adherence level assessment), and Part 4 (the impact of the pandemic on hypertension control) are $0.6,0.9$, and 0.7 , respectively. These obtained values excluded the presence of poor or unacceptable items [20]. Therefore, the questionnaire was then finalised and disseminated for the main data collection.

\subsection{Data Collection}

The final survey was distributed through online media, mainly social media platforms (Facebook and WhatsApp), using the convenience sampling method. The online medium was used to disseminate the survey form to avoid the additional risk of face-to-face interaction during the current COVID-19 restrictions. A minimum of three weekly reminders were sent throughout the twelve weeks dedicated for data collection. The total scores of health literacy, adherence, and pandemic impact were calculated for each participant. Higher scores for health literacy (total $=5$ ) and adherence (total $=24$ ) are direct measures of their levels, while higher scores of the pandemic impact $($ total $=24)$ denote greater negative impact of the pandemic on blood pressure control from patients' perspectives.

\subsection{Statistical Analysis}

Data were analysed using statistical package for the social sciences (SPSS-10 Inc., Chicago, IL, USA) version 22.0. The responses were analysed using descriptive statistics in the form of frequencies and percentages. The total scores for three of the main variables: health literacy, adherence, and impact of the pandemic of each participant, were calculated. The association between the categorical variables was examined using chi-square test. The significance of the differences between patients' demographics, blood pressure control as categorical variables, and the total scores of all three main continuous variables were examined using Mann-Whitney and Kruskal-Wallis tests, considering they did not meet the assumption of normal distribution [21,22]. A $p$-value of $<0.05$ was set as the significance level for all comparisons.

\section{Results}

\subsection{Demographics of Study Participants and Their Blood Pressure Control}

A total of 144 patients consented to participate in the study. About $68.8 \%$ of respondents were $40-59$ years old, and $51.4 \%$ were female. Moreover, $44.4 \%$ of respondents were in the household income group of M40, meaning their income was between RM 4850 to 10,959. Participants were categorised into two main groups, controlled and uncontrolled BP, referring to their average measured BP over the last seven days. Controlled blood pressure was reported in $77 \%(\mathrm{~N}=111)$. Frequencies and percentages of participants' demographic details are summarised in Table 1.

\subsection{Health Literacy}

\subsubsection{Health Literacy (Overall Responses)}

The total score for the health literacy part that consisted of five items was five. Total health literacy score median $=4$ and interquartile range $(I Q R)=2$. Higher scores were regarded as indicators of good health literacy. Table 2 summarises the overall responses to health literacy items presented in frequencies and percentages. 
Table 1. Demographics of study participants and their BP control.

\begin{tabular}{|c|c|c|}
\hline & requency & Percentage \\
\hline \multicolumn{3}{|c|}{ Age Groups } \\
\hline $18-39$ & 27 & 18.8 \\
\hline $40-59$ & 99 & 68.8 \\
\hline 60 or more & 18 & 12.5 \\
\hline \multicolumn{3}{|c|}{ Gender } \\
\hline Male & 70 & 48.6 \\
\hline Female & 74 & 51.4 \\
\hline \multicolumn{3}{|c|}{ Ethnicity } \\
\hline Malay & 141 & 97.9 \\
\hline Chinese & 3 & 2.1 \\
\hline \multicolumn{3}{|c|}{ Marital status } \\
\hline Unmarried (single/widowed/divorced) & 21 & 14.6 \\
\hline Married & 123 & 85.4 \\
\hline \multicolumn{3}{|c|}{ Level of education } \\
\hline Pre-college education & 37 & 25.7 \\
\hline College/University & 107 & 74.3 \\
\hline \multicolumn{3}{|c|}{ Employment status } \\
\hline Unemployed/retired & 51 & 35.4 \\
\hline Employed/Self-employed & 93 & 64.6 \\
\hline \multicolumn{3}{|c|}{ Monthly household income } \\
\hline Less than RM 4850 (B40 group) & 53 & 36.8 \\
\hline RM 4850-RM 10,959 (M40 group) & 64 & 44.4 \\
\hline More than RM 10,959 (T20 group) & 27 & 18.8 \\
\hline \multicolumn{3}{|c|}{ Location of residence } \\
\hline Urban & 121 & 84.0 \\
\hline Rural & 23 & 16.0 \\
\hline \multicolumn{3}{|c|}{ Your average blood pressure reading in the past 7 days } \\
\hline $\begin{array}{l}\text { Systolic blood pressure }<140 \mathrm{mmHg} \text { and } \\
\text { diastolic blood pressure }<90 \mathrm{mmHg}\end{array}$ & 111 & 77.1 \\
\hline $\begin{array}{l}\text { Systolic blood pressure of at least } 140 \mathrm{mmHg} \\
\text { or diastolic blood pressure of at least } 90 \\
\mathrm{mmHg}\end{array}$ & 33 & 22.9 \\
\hline Total & 144 & 100.0 \\
\hline
\end{tabular}

Table 2. Overall responses to health literacy items.

\begin{tabular}{|c|c|c|}
\hline & Frequency & Percentage \\
\hline \multicolumn{3}{|c|}{$\begin{array}{l}\text { Reading of systolic blood pressure of at least } 140 \mathrm{mmHg} \text { OR diastolic blood pressure of at } \\
\text { least } 90 \mathrm{mmHg} \text { indicates UNCONTROLLED blood pressure }\end{array}$} \\
\hline No, not sure & 37 & 25.7 \\
\hline Yes & 107 & 74.3 \\
\hline \multicolumn{3}{|c|}{ Hypertension is a leading risk factor for cardiovascular diseases. } \\
\hline No, not sure & 14 & 9.7 \\
\hline Yes & 130 & 90.3 \\
\hline \multicolumn{3}{|c|}{ The treatment of hypertension among patients is a lifelong treatment. } \\
\hline No, not sure & 29 & 20.1 \\
\hline Yes & 115 & 79.9 \\
\hline \multicolumn{3}{|c|}{ Reducing the amount of salts intake in diet can reduce blood pressure level. } \\
\hline No, not sure & 32 & 22.2 \\
\hline Yes & 112 & 77.8 \\
\hline \multicolumn{3}{|c|}{$\begin{array}{l}\text { Once a person is diagnosed with hypertension, usually he or she will get cured within few } \\
\text { weeks after receiving treatment. }\end{array}$} \\
\hline Yes, not sure & 50 & 34.7 \\
\hline No & 94 & 65.3 \\
\hline Total & 144 & 100.0 \\
\hline
\end{tabular}




\subsubsection{Health Literacy (Inferential Statistics)}

A chi-square test of independence was conducted between patients' demographics and health literacy items. All expected cell frequencies were greater than five. There was a statistically significant association between gender and patient's literacy that hypertension treatment is lifelong $\left(\chi^{2}(1)=4.49, p=0.03\right)$. There was also a statistically significant association between monthly household income and the patient's literacy; hypertension cannot be cured in few weeks after initiating treatment $\left(\chi^{2}(2)=6.32, p=0.04\right)$.

\subsection{Adherence}

\subsubsection{Adherence (Overall Responses)}

The total score for the adherence part that consisted of eight items was 24 . Total adherence score median $=21$ and $\mathrm{IQR}=3$. Higher scores were regarded as indicators of good adherence. Table 3 summarises the overall responses to adherence items presented in frequencies and percentages.

Table 3. Overall responses to adherence items.

\begin{tabular}{|c|c|c|}
\hline & Frequency & Percentage \\
\hline \multicolumn{3}{|c|}{ How often do you forget to take your hypertension medicine? } \\
\hline Often/very often & 11 & 7.6 \\
\hline Sometimes & 28 & 19.4 \\
\hline Rarely/never & 105 & 72.9 \\
\hline \multicolumn{3}{|c|}{ How often do you decide NOT to take your hypertension medicine? } \\
\hline Often/very often & 17 & 11.8 \\
\hline Sometimes & 14 & 9.7 \\
\hline Rarely/never & 113 & 78.5 \\
\hline \multicolumn{3}{|c|}{ How often do you eat food rich in salts? } \\
\hline Often/very often & 50 & 34.7 \\
\hline Sometimes & 57 & 39.6 \\
\hline Rarely/never & 37 & 25.7 \\
\hline \multicolumn{3}{|c|}{ How often do you eat fast food? } \\
\hline Often/very often & 16 & 11.1 \\
\hline Sometimes & 59 & 41.0 \\
\hline Rarely/never & 69 & 47.9 \\
\hline \multicolumn{3}{|c|}{ How often do you miss scheduled appointments with doctor? } \\
\hline Often/very often & 11 & 7.6 \\
\hline Sometimes & 17 & 11.8 \\
\hline Rarely/never & 116 & 80.6 \\
\hline \multicolumn{3}{|c|}{$\begin{array}{l}\text { How often do you forget to get prescriptions filled? (Prescription is an official document } \\
\text { written by a doctor for the purpose of patient's medicine supply) }\end{array}$} \\
\hline Often/very often & 9 & 6.3 \\
\hline Sometimes & 12 & 8.3 \\
\hline Rarely/never & 123 & 85.4 \\
\hline \multicolumn{3}{|c|}{ How often do you skip taking your hypertension pills intentionally when you feel better } \\
\hline Often/very often & 14 & 9.7 \\
\hline Sometimes & 14 & 9.7 \\
\hline Rarely/never & 116 & 80.6 \\
\hline \multicolumn{3}{|c|}{ How often do you miss taking your hypertension pills when you get sick? } \\
\hline Often/very often & 11 & 7.6 \\
\hline Sometimes & 13 & 9.0 \\
\hline Rarely/never & 120 & 83.3 \\
\hline Total & 144 & 100.0 \\
\hline
\end{tabular}

\subsubsection{Adherence (Inferential Statistics)}

A Kruskal-Wallis $\mathrm{H}$ test was run to determine if there were differences in total adherence scores between the three age groups: "18-39 years", "40-59 years", and "60 years and above". Distributions of total adherence scores were not similar for all groups, as assessed by visual inspection of a boxplot. The distributions of total adherence scores were statis- 
tically significantly different between age groups $\left(\chi^{2}(2)=6.48, p=0.039\right)$. Subsequently, pairwise comparisons were performed using Dunn's (1964) procedure with a Bonferroni correction for multiple comparisons. Adjusted $p$-values are presented. Values are mean ranks unless otherwise stated. This post hoc analysis revealed statistically significant differences in total adherence scores between the "60 years and above" group (95.42) and "40-59 years" group (69.99) ( $p=0.049)$, but not between any other group combination.

A Mann-Whitney $U$ test was run to determine differences in total adherence scores between those who reported controlled and uncontrolled blood pressure. Distributions of the total adherence scores were not similar, as assessed by visual inspection. Total adherence scores for those who reported controlled blood pressure (mean rank $=78.95$ ) were statistically significantly higher than for those reported uncontrolled blood pressure (mean rank $=50.82)(\mathrm{U}=1116, \mathrm{z}=-3.434, p=0.001)$.

\subsection{Impact of the COVID-19 Pandemic}

\subsubsection{Pandemic Impact (Overall Response)}

The total score for the pandemic impact on hypertension control that consisted of eight items was 24. Total pandemic impact scores median $=12$ and $\mathrm{IQR}=4.8$. Higher scores were regarded as indicators of the negative impact of the pandemic on hypertension control. Table 4 summarises the overall responses to pandemic impact items presented in frequencies and percentages.

\subsubsection{Pandemic Impact (Inferential Statistics)}

A chi-square test of independence was conducted between patients' demographics and pandemic impact items. All expected cell frequencies were greater than five. There was a statistically significant association between gender and perception that hypertension treatment became more complex during the pandemic than before $\left(\chi^{2}(2)=5.93, p=0.05\right)$. Also, there was a statistically significant association between level of education and the individual's perspective on more reliance on self-monitoring of BP during the pandemic $\left(\chi^{2}(2)=6.41, p=0.04\right)$.

A Kruskal-Wallis $\mathrm{H}$ test was conducted to determine if there were differences in total pandemic impact scores between the three age groups: "18-39 years", "40-59 years", and "60 years and above" and three household income groups: "B40 (income less than $4.850 \mathrm{RM}$ )", "M40 (income in the range of 4.850-10.959 RM)", and "T20 (income above $10.959 \mathrm{RM})$ ". Distributions of total pandemic impact scores were not similar for all groups, as assessed by visual inspection of a boxplot. The distributions of pandemic impact scores had statistically significant differences between age groups $\left(\chi^{2}(2)=15.008, p=0.001\right)$ and between household income groups $\left(\chi^{2}(2)=6.887, p=0.032\right)$. Subsequently, pairwise comparisons were performed using Dunn's (1964) procedure with a Bonferroni correction for multiple comparisons. Adjusted $p$-values are presented. Values are mean ranks unless otherwise stated. This post hoc analysis revealed statistically significant differences in total pandemic impact scores between the "18-39 years" group (100.33) and both groups of "60 years and above" $(66.03)(p=0.019)$ and "40-59 years" (66.09) $(p<0.001)$. Furthermore, it revealed statistically significant differences in total pandemic impact scores between the "B40" group (84.37) and the "M40" group (65.66) ( $p=0.045)$, but not between any other group combination.

A Mann-Whitney $U$ test was conducted to determine differences in total pandemic impact scores between the employed and unemployed participants and between the married and unmarried participants. Distributions of the total pandemic impact scores were not similar, as assessed by visual inspection. Total pandemic impact scores for the unemployed participants (mean rank $=85.42$ ) were statistically significantly higher than for those employed individuals (mean rank $=65.41)(\mathrm{U}=1712, \mathrm{z}=-2.772, p=0.006)$. In addition, total pandemic impact scores for those unmarried individuals (mean rank $=109.21$ ) were statistically significantly higher than for those married individuals (mean rank $=66.23$ ) $(\mathrm{U}=520.5, \mathrm{z}=-4.395, p<0.001)$. 
Table 4. Responses to items related to items assessing the pandemic impact on hypertension control.

\begin{tabular}{|c|c|c|}
\hline & Frequency & Percentage \\
\hline \multicolumn{3}{|c|}{ During this pandemic, my blood pressure level becomes worse as compared to before. } \\
\hline Disagree/Strongly disagree & 93 & 64.6 \\
\hline Neutral & 37 & 25.7 \\
\hline Agree/Strongly agree & 14 & 9.7 \\
\hline \multicolumn{3}{|c|}{ During this pandemic, I rely more on self-monitoring of blood pressure as compared to before. } \\
\hline Agree/Strongly agree & 66 & 45.8 \\
\hline Neutral & 48 & 33.3 \\
\hline Disagree/Strongly disagree & 30 & 20.8 \\
\hline \multicolumn{3}{|c|}{$\begin{array}{l}\text { During this pandemic, I have the fear of going out to get my medications supply due to the } \\
\text { risk of COVID-19 infection as compared to before. }\end{array}$} \\
\hline Disagree/Strongly disagree & 81 & 56.3 \\
\hline Neutral & 31 & 21.5 \\
\hline Agree/Strongly agree & 32 & 22.2 \\
\hline \multicolumn{3}{|c|}{$\begin{array}{l}\text { During this pandemic, my hypertension treatment plan becomes more complex as compared } \\
\text { to before. }\end{array}$} \\
\hline Disagree/Strongly disagree & 95 & 66.0 \\
\hline Neutral & 33 & 22.9 \\
\hline Agree/Strongly agree & 16 & 11.1 \\
\hline \multicolumn{3}{|c|}{ I always practice a healthy diet during this pandemic. } \\
\hline Agree/Strongly agree & 75 & 52.1 \\
\hline Neutral & 55 & 38.2 \\
\hline Disagree/Strongly disagree & 14 & 9.7 \\
\hline \multicolumn{3}{|c|}{ Due to this pandemic, I encounter more life-stresses as compared to before. } \\
\hline Disagree/Strongly disagree & 75 & 52.1 \\
\hline Neutral & 39 & 27.1 \\
\hline Agree/Strongly agree & 30 & 20.8 \\
\hline \multicolumn{3}{|c|}{$\begin{array}{l}\text { During this pandemic, I seldom attend appointment with doctors as what had been } \\
\text { scheduled. }\end{array}$} \\
\hline Disagree/Strongly disagree & 94 & 65.3 \\
\hline Neutral & 30 & 20.8 \\
\hline Agree/Strongly agree & 20 & 13.9 \\
\hline \multicolumn{3}{|c|}{ I comply with taking the prescribed medications as scheduled during this pandemic. } \\
\hline Agree/Strongly agree & 106 & 73.6 \\
\hline Neutral & 25 & 17.4 \\
\hline Disagree/Strongly disagree & 13 & 9.0 \\
\hline Total & 144 & 100.0 \\
\hline
\end{tabular}

\section{Discussion}

To the best of our knowledge, this is one of the first studies that has investigated the impact of the COVID-19 pandemic on BP control among a sample of hypertensive patients in Malaysia. This study aimed to assess the impact of socio-demographic factors, health literacy, and adherence on the overall hypertension management during the COVID-19 pandemic. We also aimed to provide further insights on the patients' perspectives about the impact of the pandemic on their hypertension disease management. The findings showed that a total of $77 \%(\mathrm{~N}=111)$ participants had their BP under control. Our findings contrast to a previous study that included Asian patients and reported $62.4 \%$ of their study subjects to have uncontrolled BP [21]. Overall, most participants had good levels of health literacy and adherence. However, overall responses did not support a significant impact of the pandemic on hypertension control where about $77 \%$ of patients attained their target BP; there were many significant barriers to optimal hypertension disease management imposed by the pandemic.

\subsection{Health Literacy}

The overall reported level of health literacy among study participants was good, with a median score of four out of five. In a recent cross-sectional study conducted in Iran in 2020 among 210 patients, the findings showed that adequate health literacy was 
significantly associated with hypertension control [23]. Similarly, a study conducted in Uzbekistan in 2014 involving 209 hypertensive patients also reported a significant association between good hypertension knowledge and controlled BP [24]. On the other hand, a Turkish cross-sectional study in 2016 that involved 485 hypertensive patients in determining the effect of hypertension knowledge on blood pressure control found no significant correlation between the level of knowledge and the ratio of subjects with controlled blood pressure [25]. Furthermore, a study investigating the role of health literacy in hypertension control suggested that health information should be considered a critical part of hypertension management [23].

\subsection{Health Literacy and Socio-Demographics}

Moreover, our study findings demonstrated a statistically significant association between gender and patients' literacy that hypertension treatment is lifelong $\left(\chi^{2}=4.49\right.$, $p=0.03$ ). Male respondents were more aware of the lifelong nature of hypertension compared to female participants. Consistently, a 2017 Chinese study that investigated the association between health literacy and hypertension management reported that more males were in the high health literacy group [9]. This point could be relevant in designing and implementing health awareness campaigns focusing on enhancing females' awareness.

Furthermore, our findings reported a statistically significant association between monthly household income and patients' literacy that hypertension cannot be cured in a few weeks after initiating treatment $\left(\chi^{2}=6.32, p=0.04\right)$. Participants in the highest monthly income group were the most knowledgeable that hypertension is a chronic condition compared to lower-income groups. Considering patients' economic status and how it affects their awareness and ability to maintain proper disease management is critical, especially during the pandemic period, which has resulted in several economic challenges to individuals and the health care system [26].

\subsection{Adherence}

The overall level of adherence among study participants was good, with an average score of 20.5 out of 24 . Numerous studies, including two conducted locally, also reported high adherence among most hypertensive participants [27-33]. In 2013, the COMFORT study that included 203 hypertensive Japanese patients reported the highest level of adherence, with $90.6 \%$ reporting an adherence rate of $90-100 \%$ [29]. Our study incorporated three elements of adherence in the questionnaire: medications, diet, and follow-up appointments to measure patients' adherence to the overall treatment plan and how it affected their BP control. We found a significant association between total adherence scores and BP control $(\mathrm{U}=1116, p=0.001)$. This finding is consistent with the findings from several other studies [27,32-35]. For example, an Ethiopian study conducted by Animut et al. in 2018 reported that patients who were highly adherent to their antihypertensive medications were two times more likely to have controlled BP than those with low adherence [32]. Apart from that, a Nigerian study in 2018 measured treatment adherence to pharmacological and non-pharmacological therapies on 605 hypertensive patients. The findings demonstrated a significant association between treatment adherence (medications, smoking cessation, and exercise) with BP control, particularly baseline systolic BP [36].

\subsection{Adherence \& Socio-Demographics}

Several factors may influence patients' adherence. In our findings, the age group was the only demographic data that showed a significant difference in the total adherence scores. The older age group (60 or more) obtained higher scores than the younger group of 40-59 years. It seemed that the older population was more concerned about their medication adherence during the pandemic, considering a recent report in 2020 published by researchers in Iran and the UK that discussed the role of fear of COVID-19 on preventive behaviours [37]. It may also be attributed to the extra care given to this vulnerable population during this challenging time to avoid the undesired consequences, 
recognising forgetfulness as one of the top barriers to medication adherence [35,36]. Previous research from Malaysia in 2020 reported that a longer duration of hypertension, medication side effects, and use of traditional medicine were among the predictors of medication non-adherence among hypertension patients [31]. These factors should be addressed by healthcare providers and patients to optimise medication adherence and clinical outcomes [38].

\subsection{Pandemic Impact}

In measuring the impact of the pandemic on hypertension from patients' perspectives, we incorporated essential aspects concerning the pandemic and BP control in the questionnaire. These aspects included worsening BP level, increased reliance on self-monitoring, the challenge of getting medication supplies due to COVID-19 infection risk, changes in the treatment plan, adherence to healthy diet and medications, and life-stresses. The total pandemic impact score median of 12 on a scale of 24, suggesting that there was an impact, but this negative impact was not enormous across all items. Patients in our study seem to face challenges with the pandemic related-lockdowns and COVID-19-related movement restrictions to ensure adequate medication supplies. Moreover, they had been exposed to increased life stressors in the pandemic time. In addition, they had found themselves enforced to be more dependent on self-monitoring as compared to the time prior to the pandemic. A recent report from Malaysia discussed the challenges with proceeding with optimal care for chronic conditions during the pandemic and reported concerns on medication supply and self-monitoring needs as predicted challenges in this time [15].

\subsection{Pandemic Impact and Socio-Demographics}

Importantly, our findings provided insights into the characteristics of patients who were more likely to be negatively affected by the pandemic while maintaining their hypertension control. We found a statistically significant association between gender and the perception that hypertension treatment became more complex during the pandemic than before. Females were more likely to disagree with the increased complexity of hypertension treatment than males. Concerning the gender impact on BP control, several studies reported that male patients were more prone to have poor BP control $[34,39,40]$. Meanwhile, in 2016, another Brazilian study consistently reported that females were more likely to report uncontrolled BP than males [41].

Furthermore, there was a statistically significant association between level of education and the individual's perspective on more reliance on self-monitoring of blood pressure during the pandemic. Those with higher education seem to be more concerned about their disease management in terms of increased reliance on BP self-monitoring than the other group. In addition, a Canadian study conducted by Gee et al. in 2012 reported that a higher rate of uncontrolled BP was observed among people with low education levels [42].

Moreover, the analysis revealed statistically significant differences in total pandemic impact scores based on age, household income, employment, and marital status. The youngest age group (18-39 years), the lowest income group (B40), unemployed and unmarried individuals had significantly higher pandemic impact scores. This infers that those individuals were more prone to be affected negatively by the pandemic and consequently had more significant challenges to maintain proper hypertension control under this strain. In relation, a recent Singapore study found that being younger, male, and having a lower educational level were all associated with untreated hypertension [43]. However, some studies have suggested that old age is considered as a barrier to optimal BP control and a strong predictor of uncontrolled HTN according to reported data from Singapore and Sweden, respectively $[43,44]$. In addition, the evidence from an Iraqi study did not support the significant impact of education and employment on the control of BP among hypertensive patients [34].

According to a Nigerian study conducted in 2014, the financial constraints showed an adverse impact on medication adherence, leading to the sub-optimal achievement of 
BP control [45]. Overall, socio-economically under-privileged people were more likely to show a strong pattern toward the greater risk of having sub-optimal BP level despite treatment [42]. This might underpin the need for customised interventions to target BP control improvement among those individuals with particular socio-economic challenges. Overall, identification of these patients who might have increased challenges with their disease management during the pandemic might suggest a role for relevant health authorities in executing appropriate public health measures and policies to ensure the maintenance of good hypertension management during the ongoing pandemic.

\subsection{Study Limitations}

This study has some limitations, including a relatively small sample (despite repeated and frequent reminders and an extended period of data collection); this could have potentially affected the generalizability of the results to a wider hypertensive population in Malaysia. Moreover, the cross-sectional study design did not allow for assessing the causal relationship. Data could only be collected via an online survey as this was the only probable safe method of data collection amidst the COVID-19-related-restrictions. Additionally, as the survey link was prepared on Google Forms and disseminated through social media, the elderly and those participants without internet access or without social media or Google Forms' knowledge could not have participated in the study. Furthermore, convenience sampling might have limited the possibility of the sample being representative and predisposed this study to a potential selection bias [46]. Finally, the self-administered questionnaire could have led to potential recall bias [47].

\subsection{Practical Implications and Future Research}

The protracted and unprecedented nature of the current pandemic and the extended challenges warrant an urgent need to optimise care for patients with chronic diseases, such as hypertension. Identifying those patients' groups at increased risk of developing adverse pandemic impact would help to tailor initiatives, such as online educational programs and innovative tools to assist them in maintaining optimal disease management. Future research should concentrate on testing these findings on a large scale and include a followup period to enhance our understanding of how these perceptions and challenges vary over time.

\section{Conclusions}

Most participants reported relatively controlled blood pressure and good levels of health literacy and adherence amid the pandemic. To a moderate extent, study participants perceived that the pandemic had a negative effect on hypertension management. The perceived negative impact of the pandemic was attributed to several socio-demographic factors, such as age, household income, employment, and marital status. These findings may help in identifying the patient groups at higher risk of the pandemic impact to be targeted by relevant initiatives.

Author Contributions: Conceptualisation, M.H.E.; methodology, M.H.E. and N.H.K.; validation, M.H.E. and N.H.K.; formal analysis, M.H.E. and N.H.K.; resources, N.K.S.; writing-original draft preparation, M.H.E. and N.H.K.; writing-review and editing, H.Z.H., I.S.D. and E.C.; visualisation, H.Z.H., E.C. and N.K.S.; supervision, M.H.E., H.Z.H.; project administration, M.H.E., I.S.D. and E.C. All authors have read and agreed to the published version of the manuscript.

Funding: This study is supported by grant no. RC-RIGS20-006-0006 from the research management centre, International Islamic University Malaysia.

Institutional Review Board Statement: The Ethical approval for this study was approved by IIUM Research Ethics Committee (IREC 2020-176). The participation information sheet and informed consent form were included in the online survey form. By approving the consent form, participants were deemed to have agreed to the terms and conditions of this research. They were also given the freedom to withdraw their consent to participate without any loss at any time. 
Informed Consent Statement: Informed consent was obtained from all subjects involved in the study.

Acknowledgments: The first and corresponding author M.H.E. and the author, N.K.S. would like to dedicate this manuscript to their respective beloved fathers (Hassan Abdelaziz Elnaem \& Alhaj Syed Maqbool) who passed away.

Conflicts of Interest: The authors declare no conflict of interest.

\section{References}

1. World Health Organization. Hypertension. 2019. Available online: https://www.who.int/news-room/fact-sheets/detail/ hypertension (accessed on 12 January 2021).

2. Sawicka, K.; Szczyrek, M.; Jastrzębska, I.; Prasał, M.; Zwolak, A.; Daniluk, J. Hypertension—The Silent Killer. J. Pre-Clin. Clin. Res. 2011, 5, 43-46.

3. Ab Majid, N.L.; Omar, M.A.; Khoo, Y.Y.; Naidu, B.M.; Yn, J.L.M.; Hasani, W.S.R.; Rifin, H.M.; Hamid, H.A.A.; Lourdes, T.G.R.; Yusoff, M.F.M. Prevalence, Awareness, Treatment and Control of hypertension in the Malaysian population: Findings from the National Health and Morbidity Survey 2006-2015. J. Hum. Hypertens. 2018, 32, 617-624. [CrossRef]

4. Ministry of Health Malaysia. Non-Communicable Diseases: Risk Factors and Other Health Problems; National Health and Morbidity Survey 2019-Technical Report 2019; Volume 1, pp. 1-392. Available online: https://www.researchgate.net/publication/34685673 6_NHMS_2019_-_Non-Communicable_Diseases_Risk_Factors_and_other_health_problems (accessed on 4 July 2021).

5. Hasani, W.S.R.; Ganapathy, S.S.; Lin, C.Z.; Rifin, H.M.; Bahari, M.N.; Ghazali, M.H.; Lodz, N.A.; Ramli, M.H.T.; Ab Majid, N.L.; Ling, M.Y.J.; et al. Comorbidities and clinical features related to severe outcomes among COVID-19 cases in Selangor, Malaysia. West. Pac. Surveill. Response J. WPSAR 2021, 12, 46-52. [CrossRef] [PubMed]

6. Hashim, J.H.; Adman, M.A.; Hashim, Z.; Radi, M.F.M.; Kwan, S.C. COVID-19 Epidemic in Malaysia: Epidemic Progression, Challenges, and Response. Front. Public Health 2021, 9, 560592. [CrossRef] [PubMed]

7. Saqlain, M.; Riaz, A.; Malik, M.N.; Khan, S.; Ahmed, A.; Kamran, S.; Ali, H. Medication Adherence and Its Association with Health Literacy and Performance in Activities of Daily Livings among Elderly Hypertensive Patients in Islamabad, Pakistan. Medicina 2019, 55, 163. [CrossRef]

8. Krousel-Wood, M.A.; Muntner, P.; Islam, T.; Morisky, D.E.; Webber, L.S. Barriers to and Determinants of Medication Adherence in Hypertension Management: Perspective of the Cohort Study of Medication Adherence among Older Adults. Med. Clin. N. Am. 2009, 93, 753-769. [CrossRef]

9. Shi, D.; Li, J.; Wang, Y.; Wang, S.; Liu, K.; Shi, R.; Zhang, Q.; Chen, X. Association between health literacy and hypertension management in a Chinese community: A retrospective cohort study. Intern. Emerg. Med. 2017, 12, 765-776. [CrossRef] [PubMed]

10. Magnani, J.W.; Mujahid, M.S.; Aronow, H.D.; Cené, C.W.; Dickson, V.V.; Havranek, E.; Morgenstern, L.B.; Paasche-Orlow, M.K.; Pollak, A.; Willey, J.Z.; et al. Health Literacy and Cardiovascular Disease: Fundamental Relevance to Primary and Secondary Prevention: A Scientific Statement From the American Heart Association. Circulation 2018, 138, e48-e74. [CrossRef] [PubMed]

11. Jimmy, B.; Jose, J. Patient Medication Adherence: Measures in Daily Practice. Oman Med. J. 2011, 26, 155-159. [CrossRef]

12. Burnier, M.; Egan, B.M. Adherence in Hypertension. Circ. Res. 2019, 124, 1124-1140. [CrossRef]

13. Sim, M.R. The COVID-19 pandemic: Major risks to healthcare and other workers on the front line. Occup. Environ. Med. 2020, 77, 281-282. [CrossRef]

14. Wold Health Organization. WHO the Impact of the COVID-19 Pandemic on Non-Communicable Disease Resources and Services: Results of a Rapid Assessment. Available online: https://www.who.int/teams/noncommunicable-diseases/covid-19\%0Ahttps: / / www.who.int/publications/i/item/ncds-covid-rapid-assessment (accessed on 28 August 2021).

15. Elnaem, M.H.; Cheema, E. Caring for patients with diabetes during COVID-19 pandemic: Important considerations for pharmacists. Res. Soc. Adm. Pharm. 2021, 17, 1938-1941. [CrossRef]

16. Kario, K.; Morisawa, Y.; Sukonthasarn, A.; Turana, Y.; Chia, Y.; Park, S.; Wang, T.; Chen, C.; Tay, J.C.; Li, Y.; et al. COVID-19 and hypertension-Evidence and practical management: Guidance from the HOPE Asia Network. J. Clin. Hypertens. 2020, 22, 1109-1119. [CrossRef] [PubMed]

17. OMS WHO. Director-General's Opening Remarks at the Media Briefing on COVID-19-11 March 2020. Available online: https:/ / www.who.int/director-general/speeches/detail/who-director-general-s-opening-remarks-at-the-media-briefing-oncovid-19---11-march-2020\%0Ahttps: / / www.who.int/dg/speeches/detail/who-director-general-s-opening-remarks-at-themedia-briefing-on-covid-19 (accessed on 11 March 2020).

18. Kim, M.T.; Hill, M.N.; Bone, L.R.; Levine, D.M. Development and testing of the Hill-Bone Compliance to High Blood Pressure Therapy Scale. Prog. Cardiovasc. Nurs. 2000, 15, 90-96. [CrossRef] [PubMed]

19. Almanasreh, E.; Moles, R.; Chen, T.F. Evaluation of methods used for estimating content validity. Res. Soc. Adm. Pharm. 2019, 15, 214-221. [CrossRef] [PubMed]

20. Cronbach's Alpha: Simple Definition, Use and Interpretation-Statistics How to. Available online: https:/ / www.statisticshowto. $\mathrm{com} /$ probability-and-statistics/statistics-definitions/cronbachs-alpha-spss/ (accessed on 27 August 2021).

21. Harpe, S.E. How to analyse Likert and other rating scale data. Curr. Pharm. Teach. Learn. 2015, 7, 836-850. [CrossRef]

22. Vargha, A.; Delaney, H.D. The Kruskal-Wallis Test and Stochastic Homogeneity. J. Educ. Behav. Stat. 1998, 23, 170-192. [CrossRef] 
23. Ghaffari-Fam, S.; Sarbazi, E.; Ardabili, F.; Babazadeh, T.; Darghahi, G.; Jafaralilou, H. The role of Health Literacy in Hypertension Control: A cross-sectional study in Iran. Ann. di Ig. Med. Prev. e di Comunita 2020, 32, 263-273.

24. Malik, A.; Yoshida, Y.; Erkin, T.; Salim, D.; Hamajima, N. Hypertension-Related Knowledge, Practice and Drug Adherence among Inpatients of a Hospital in Samarkand, Uzbekistan. Nagoya J. Med. Sci. 2014, 76, 255-263.

25. Kilic, M.; Uzunçakmak, T.; Ede, H. The effect of knowledge about hypertension on the control of high blood pressure. Int. J. Cardiovasc. Acad. 2016, 2, 27-32. [CrossRef]

26. Kreutz, R.; Dobrowolski, P.; Prejbisz, A.; Algharably, E.A.-H.; Bilo, G.; Creutzig, F.; Grassi, G.; Kotsis, V.; Lovic, D.; Lurbe, E.; et al. Lifestyle, psychological, socio-economic and environmental factors and their impact on hypertension during the coronavirus disease 2019 pandemic. J. Hypertens. 2021, 39, 1077-1089. [CrossRef]

27. Jhaj, R.; Gour, P.R.; Kumari, S.; Sharma, S. Association between medication adherence and blood pressure control in urban hypertensive patients in central India. Int. J. Noncommun. Dis. 2018, 3, 9. [CrossRef]

28. Li, Y.T.; Wang, H.H.; Liu, K.Q.; Lee, G.K.; Chan, W.M.; Griffiths, S.M.; Chen, R.L. Medication Adherence and Blood Pressure Control Among Hypertensive Patients With Coexisting Long-Term Conditions in Primary Care Settings. Medicina 2016, 95 , e3572. [CrossRef]

29. Matsumura, K.; Arima, H.; Tominaga, M.; Ohtsubo, T.; Sasaguri, T.; Fujii, K.; Fukuhara, M.; Uezono, K.; Morinaga, Y.; Ohta, Y.; et al. Impact of antihypertensive medication adherence on blood pressure control in hypertension: The COMFORT study. QJM Int. J. Med. 2013, 106, 909-914. [CrossRef]

30. Ramli, A.; Ahmad, N.S.; Paraidathathu, T. Medication adherence among hypertensive patients of primary health clinics in Malaysia. Patient Prefer. Adherence 2012, 6, 613-622. [CrossRef] [PubMed]

31. Yusoff, N.H.; Binti, M.; Sook, J.L.W.; Jun, S.M.; Mooi, C.S. Prevalence and factors associated with medication noncompliance among patients with hypertension in a tertiary hospital: A cross-sectional study in Malaysia. Malays. J. Med. Health Sci. 2020, 16, 36-42.

32. Animut, Y.; Assefa, A.T.; Lemma, D.G. Blood pressure control status and associated factors among adult hypertensive patients on outpatient follow-up at University of Gondar Referral Hospital, northwest Ethiopia: A retrospective follow-up study. Integr. Blood Press. Control 2018, 11, 37-46. [CrossRef]

33. Menanga, A.; Edie, S.; Nkoke, C.; Boombhi, J.; Musa, A.J.; Mfeukeu, L.K.; Kingue, S. Factors associated with blood pressure control amongst adults with hypertension in Yaounde, Cameroon: A cross-sectional study. Cardiovasc. Diagn. Ther. 2016, 6, 439-445. [CrossRef] [PubMed]

34. Nassr, O.A.; Forsyth, P. Evaluation of blood pressure control and associated factors among patients with hypertension in Iraq: A prospective cross-sectional study. J. Pharm. Bioallied Sci. 2019, 11, 232-239. [CrossRef]

35. Iloh, G.U.P.; Ofoedu, J.N.; Njoku, P.U.; Amadi, A.N.; Godswill-Uko, E.U. Medication adherence and blood pressure control amongst adults with primary hypertension attending a tertiary hospital primary care clinic in Eastern Nigeria. Afr. J. Prim. Health Care Fam. Med. 2013, 5, 1-6. [CrossRef]

36. Adisa, R.; Ilesanmi, O.A.; Fakeye, T.O. Treatment adherence and blood pressure outcome among hypertensive out-patients in two tertiary hospitals in Sokoto, Northwestern Nigeria. BMC Cardiovasc. Disord. 2018, 18, 194. [CrossRef] [PubMed]

37. Pakpour, A.H.; Griffiths, M. The fear of COVID-19 and its role in preventive behaviors. J. Concurr. Disord. 2020, $2,58-63$.

38. Elnaem, M.H.; Rosley, N.F.F.; Alhifany, A.A.; E Elrggal, M.; Cheema, E. Impact of Pharmacist-Led Interventions on Medication Adherence and Clinical Outcomes in Patients with Hypertension and Hyperlipidemia: A Scoping Review of Published Literature. J. Multidiscip. Health 2020, 13, 635-645. [CrossRef] [PubMed]

39. Chowdhury, E.K.; on behalf of the Second Australian National Blood Pressure Study Management Committee; Owen, A.; Krum, H.; Wing, L.M.H.; Ryan, P.; Nelson, M.R.; Reid, C.M. Barriers to achieving blood pressure treatment targets in elderly hypertensive individuals. J. Hum. Hypertens. 2013, 27, 545-551. [CrossRef] [PubMed]

40. Cordero, A.; Bertomeu-Martínez, V.; Mazón, P.; Fácila, L.; Bertomeu-Gonzalez, V.; Cosin, J.; Galve, E.; Núñez, J.; Lekuona, I.; González-Juanatey, J.R. Factors Associated With Uncontrolled Hypertension in Patients With and Without Cardiovascular Disease. Rev. Española Cardiol. 2011, 64, 587-593. [CrossRef] [PubMed]

41. Wachholz, P.A.; Masuda, P.Y.; Ferrari, A.C.; Boas, P.J.F.V. Factors related to blood pressure control in a prospective cohort of hypertensive outpatients. Acta Sci. Health Sci. 2016, 38, 57. [CrossRef]

42. Gee, M.; Bienek, A.; Campbell, N.R.; Bancej, C.M.; Robitaille, C.; Kaczorowski, J.; Joffres, M.; Dai, S.; Gwadry-Sridar, F.; Nolan, R.P. Prevalence of, and Barriers to, Preventive Lifestyle Behaviors in Hypertension (from a National Survey of Canadians With Hypertension). Am. J. Cardiol. 2012, 109, 570-575. [CrossRef]

43. Liew, S.J.; Lee, J.T.; Tan, C.S.; Koh, C.H.G.; Van Dam, R.; Müller-Riemenschneider, F. Sociodemographic factors in relation to hypertension prevalence, awareness, treatment and control in a multi-ethnic Asian population: A cross-sectional study. BMJ Open 2019, 9, e025869. [CrossRef]

44. Chmiel, C.; Wang, M.; Senn, O.; Del Prete, V.; Zoller, M.; Rosemann, T.; Steurer-Stey, C. Uncontrolled arterial hypertension in primary care-patient characteristics and associated factors. Swiss Med. Wkly. 2012, 142, w13693. [CrossRef]

45. Okwuonu, C.G.; Ojimadu, N.; Akemokwe, F.; Okaka, E. Patient-related barriers to hypertension control in a Nigerian population. Int. J. Gen. Med. 2014, 7, 345-353. [CrossRef] 
46. Gobo, G. Sampling, Representativeness and Generalizability. In Qualitative Research Practice; SAGE Publications Ltd.: London, UK, 2011; pp. 405-426.

47. Khare, S.R.; Vedel, I. Recall bias and reduction measures: An example in primary health care service utilisation. Fam. Pract. 2019, 36, 672-676. [CrossRef] 